\title{
A AUSÊNCIA DE UMA EFETIVA POLÍTICA CARCERÁRIA COMO CONSEQUÊNCIA DO NÃO ATENDIMENTO DO PRIMADO DA DIGNIDADE DA PESSOA HUMANA DAS PESSOAS PRESAS ${ }^{1}$
}

THE ABSENCE OF AN EFFECTIVE PRISON POLICY AS A RESULT OF FAILURE TO RESPOND TO THE PRIMACY OF THE DIGNITY OF THE HUMAN PERSON IN PRISONERS

Monah MARTINS ${ }^{2}$

André Luis Jardini BARBOSA ${ }^{3}$

ISSUE DOI: 10.21207/2675-0104.2019.877

\section{RESUMO}

A presente pesquisa procurou analisar a eficiência do sistema carcerário, no que diz respeito ao primado da dignidade humana. Analisando-se a etapa de execução penal, enquanto momento sucessivo da sentença penal condenatória, a discussão sobre o tema se mostra relevante, uma vez que, afirmada a violação a essa dignidade, será preciso questionar a necessidade de estabelecimento de novas formas de punição, desapegado de um aspecto meramente punitivo. $\mathrm{O}$ trabalho não tem por finalidade esgotar

\footnotetext{
${ }^{1} \mathrm{O}$ presente artigo sintetiza a monografia de conclusão da pesquisa, realizada para o Programa Interno de Bolsas de Iniciação Científica (PIBIC 2018-2019) da Faculdade de Direito de Franca (FDF), Franca/SP.

${ }^{2}$ Discente da Faculdade de Direito de Franca (FDF), Franca/SP. Bolsista do Programa Interno de Bolsas de Iniciação Científica (PIBIC 2018-2019).

${ }^{3}$ Delegado de Polícia e professor universitário das Faculdade Dr. Francisco Maeda (FAFRAM) e da Faculdade de Direito Anhanguera de Franca. Doutor em Direito pela Faculdade Autônoma de Direito/FADISP - campus de São Paulo. Mestre em Direito pela UNESP/Franca. Especialista em Direito Processual Penal pela Escola Paulista da Magistratura/EPM. Professor Concursado das Cadeiras de Inquérito Policial e Investigação Policial da Academia de Polícia "Doutor Coriolano Nogueira Cobra”. E-mail: draljbarbosa@yahoo.com.br
} 
ou elucidar as temáticas aqui envolvidas, mas mostrar a relevância, na medida em que contribui com o debate em torno do tema.

Palavras-chave: Sistema Carcerário. Eficiência. Dignidade da Pessoa Humana. Pessoas Presas. ABSTRACT

This research sought to analyze the efficience of the prison system regarding the primacy of human dignity. Analyzing the stage of criminal execution, the discussion on the subject is relevant, since, once the violation of dignity is confirmed, it will be necessary to evaluate the need for new forms of punishment, detached from a merely punitive aspect. This research does not have the purpose to exhaust or elucidate the themes involved, but to show their relevance, as it contributes to the debate over this subject.

Keywords: Prison System. Efficiency. Dignity of the Human Person. People Arrested.

\section{INTRODUÇÃO}

Nas relações de efetividade e do respeito à dignidade humana do sistema carcerário existem inúmeras situações antagônicas, vez que podem estar diretamente ligadas à recuperação dos detentos e ao retorno e convívio em sociedade.

É dentro dessa perspectiva que se passou a questionar se os direitos dos detentos estão sendo respeitados. A falta de políticas públicasprincipalmente aquelas ligadas às condições das pessoas presas-, além da conhecida demora dos processos, permitiria, ao menos em princípio, repensar a eficiência do sistema judiciário brasileiro no que diz respeito ao tema.

O desejo pela reforma do código penal é para grande parte a solução dos problemas, porém esquecem-se, contudo, que a solução seria o efetivo cumprimento das leis que já existem, assim como o fortalecimento de penas alternativas o que ensejaria no mais efetivo cumprimento do primado da dignidade humana, que é, em verdade, a base prévia para o reconhecimento de todos os demais direitos.

A elevada população carcerária no Brasil vai muito além da capacidade do sistema carcerário nacional, nos colocando diante de problemas que envolvem diretamente os direitos humanos e o princípio da dignidade humana, pois na maioria das vezes o sistema carcerário não busca a recuperação do indivíduo, mas seu sofrimento, sendo deixado em situações desumanas.

Com base nesses fatores, o artigo científico buscou identificar e evidenciar quais são os fatores que contribuem para ineficácia desse sistema, descrevendo o seu funcionamento, a partir de levantamento bibliográfico e documental, e visita à uma instituição carcerária. 
Atualmente o jurisdicionado e os operadores do direito, estão na busca da celeridade, procurando outros meios de aplicação da justiça através dos instrumentos processuais disponíveis, sem procrastinar a solução dos conflitos. O processo deve ser célere e as tramitações que perduram por anos, não podem ser admitidas, pois não alcançarão objetivo da tutela jurisdicional, de justapor o poder-dever do Estado de declarar e efetivar o direito postulado.

\section{OS DIREITOS FUNDAMENTAIS SUA EVOLUÇÃO E APLICAÇÃO}

Os direitos fundamentais surgiram com a necessidade de proteger o homem do poder estatal desmedido, a partir dos ideais advindos do Iluminismo. Ganharam maior respeito a partir da concepção constitucionalista dos Estados, que passava a exigir uma limitação aos detentores do poder.

Estes podem ser definidos como o conjunto de direitos e garantias do ser humano, decorrente do fato de integrarem a raça humana. São, portanto, inatos e inerentes a essa mesma condição, o que faz com que eles venham a ser antecedentes ao próprio Direito.

A finalidade destes direitos é assegurar o respeito à dignidade humana, com limitação ao poder estatal e a garantia das condições mínimas de vida e desenvolvimento do ser humano, ou seja, o respeito à vida, à liberdade, à igualdade e à dignidade, para o pleno desenvolvimento de sua personalidade ${ }^{4}$.

Os direitos humanos ao longo dos anos passaram por três dimensões. Estas refletem o caráter acumulativo de reconhecimento de direitos e proteção, deixando claro que eles não são superados, e sim, acumulados.

A primeira dimensão dos direitos humanos ficou marcada pela miséria agravada pela revolução industrial e pela liberal-democracia que triunfava na época, fazendo com que o Estado simplesmente ignorasse problemas sociais por um capitalismo desumano.

A segunda dimensão dos direitos humanos surgiu de lutas sociais marcadas pelas desigualdades sociais, as quais pessoas buscavam maior proteção do desenvolvimento social, ou seja, buscavam um Estado de

\footnotetext{
${ }^{4}$ SILVA, José Afonso da.
} 
Bem-Estar Social, pedindo a este que garantisse a todos uma condição de igualdade, por meio de oportunidades iguais para todos, e de políticas públicas, que seriam o acesso básico à saúde, educação.

A terceira dimensão dos direitos humanos se consagrou por conta da ineficácia do Estado de atender a tudo aquilo que vinha sendo pleiteado devido à falta de recursos, e por isso, fez com que todos aqueles ideais fossem utópicos.

Esta terceira fase surgiu do apelo em massa da sociedade por mudanças no cenário atual que viviam, visando a preservação de interesses coletivos sobre os individuais, a proteção da natureza, preservação dos patrimônios culturais, a qualidade de vida em todos os ambientes, tanto rural quanto urbano, a comunicação social, o amplo acesso à informação, a ampliação de direitos políticos, a autodeterminação dos povos. Buscavam uma efetivação dos aspectos inerentes à condição humana, voltando o olhar para o lado da coletividade, não mais priorizando interesses que favoreçam apenas a uma classe ou grupo de pessoas.

Por ter como escopo a limitação e a função de restringir o exercício do poder que é conferido ao Estado, nenhuma norma pode prejudicar os direitos fundamentais, por piores que elas sejam. A não ser que haja estado de exceção. Os chamados Direitos Fundamentais podem ser considerados como elementos limitativos da Constituição Federal.

Inciso LIV, do Art $5^{\circ}$ da CF, ao dispor que: "ninguém será privado da liberdade ou de seus bens sem o devido processo legal".

E inciso LV do mesmo artigo que preceitua que: "aos litigantes, em processo judicial ou administrativo, e aos acusados em geral são assegurados o contraditório e ampla defesa com os meios e recursos a ela inerentes ${ }^{5}$.

\section{O SISTEMA CARCERÁRIO NACIONAL, A APLICAÇÃO DA PENA E A OBSERVÂNCIA DE SUAS FINALIDADES}

O sistema de cumprimento da pena no Brasil passa, necessariamente, por três etapas, sendo a primeira delas a do Inquérito Policial, que é um procedimento de natureza administrativa, portanto não se trata de processo. Sua função é preservadora e preparatória, não

\footnotetext{
${ }^{5}$ (RIVAS, 2016, s/n).
} 
deixando assim que se instaure um processo sem necessidade, mas contribui de forma que se este for instaurado, possa forneçer os elementos de informação, acautelando ainda algumas provas que podem desaparecer com o decurso do tempo ${ }^{6}$.

A segunda etapa consiste no processo legalmente instaurado após o inquérito, com respeito às formas legais, preservando os pressupostos processuais, do qual resultará uma sentença condenatória que deverá ser fundamentada pelo juiz do processo, trazendo a possível resolução do processo, possibilitando ou não a interposição de recurso para segundo $\mathrm{grau}^{7}$.

A terceira e ultima, é a fase de execução da sentença condenatória propriamente dita, ou seja, a fase na qual ocorre a aplicação da pena de forma concreta, efetiva e com cumprimento imediato.

A pena nada mais é do que a sanção imposta pelo Estado, por meio de ação penal, ao criminoso como resposta ao delito cometido e prevenção a novos crimes ${ }^{8}$. Na fixação acerca do quantum de pena não é dado ao magistrado o simples arbítrio nessa fixação, devendo obedecer a critérios de ordem objetiva e subjetiva, considerando o fato criminoso praticado e as características próprias de cada agente. É o que a doutrina denomina de individualização da pena, a qual obedece, em grande medida, ao descrito no artigo 59, do Código Penal.

Art. 59 - O juiz, atendendo à culpabilidade, aos antecedentes, à conduta social, à personalidade do agente, aos motivos, às circunstâncias e consequências do crime, bem como ao comportamento da vítima, estabelecerá, conforme seja necessário e suficiente para reprovação e prevenção do crime:

I - as penas aplicáveis dentre as cominadas;

II - a quantidade de pena aplicável, dentro dos limites previstos;

\footnotetext{
${ }^{6}$ (LIMA, 2018).

${ }^{7}$ A respeito deste tema deve ser considerado que a regra era de que a execução penal tinha início a partir da sentença penal condenatória, o que foi alterado pelo entendimento jurisprudencial, que passou a admitir a condenação a partir do acórdão confirmatório da decisão condenatória em segundo grau de jurisdição. Ou seja, passou-se a entender, ao menos até que venha a decisão definitiva do STF a respeito, que o artigo 283 do Código de Processo Penal não impede o início do cumprimento imediato da pena.
}

${ }^{8}$ (NUCCI, 2005, p 335) 
III - o regime inicial de cumprimento da pena privativa de liberdade;

IV - a substituição da pena privativa da liberdade aplicada, por outra espécie de pena, se cabível.

Critérios especiais da pena de multa

O Brasil infelizmente teve a tardia implantação da pena de prisão, e quando o fez, admitiu-a fundamentalmente com o caráter de retirada do indivíduo do seio da sociedade. Ao dizer de Goulart ${ }^{9}$, "a prisão vigorou no Brasil praticamente com o sentido de cárcere", isto é, "local de permanência temporária, ou de trânsito, para guarda de acusados que esperavam a condenação, ou mesmo a execução da pena, de regra a capital, como só ia acontecer na época".

Essa é a realidade do sistema atualmente vigente. Embora o direito brasileiro estabeleça que as penas devam ter as características de castigo, somado à intimidação e reafirmação do direito penal, mais ressocialização, vemos hoje ser cumprido o caráter meramente punitivo.

Quanto ao caráter reeducativo da pena, a lei de execução penal preceitua a assistência ao preso, e a orientação para o retorno na sociedade.

Art.10. A assistência ao preso e ao internado é dever do Estado, objetivando prevenir o crime e orientar o retorno à convivência em sociedade.

Parágrafo único. A assistência estende-se ao egresso.

Art. 22. A assistência social tem por finalidade amparar o preso e o internado e prepará-los para o retorno à liberdade

De acordo com Nucci, existem seis fundamentos para a existência da pena: a) denuncia, que faz a sociedade desaprovar a prática de alguém crime; b) dissuasão, que aconselha as pessoas a não praticarem crimes; c) incapacitação, que protege a sociedade do criminoso tirando ele de circulação; d) reabilitação, devendo reeducar o ofensor da lei penal; e) reparação, devendo trazer alguma "recompensa" à vítima; f) retribuição, que dá ao condenado uma pena proporcional ao delito por ele cometido.

$\mathrm{Na}$ pesquisa estudaremos os aspectos que tratam da natureza retributiva e restaurativa da pena, vez que nosso objeto de estudo procura

\footnotetext{
${ }^{9}$ (apud FALCONI, 1998, p. 63)
} 
questionar a efetividade do sistema carcerário como consequência do não atendimento do primado da dignidade da pessoa humana.

A retributiva cuida de deslocar suas forças para punir o infrator da lei penal, em retribuição ao mal concreto do crime com o mal concreto da pena, segundo Nelson Hungria $(1946)^{10}$. Porém com o passar do tempo, chegou uma preocupação mais condizente com os tempos atuais como a parcialidade a qual se condena pessoas hoje, sem se preocupar o mínimo possível com a condição que estas pessoas poderão se deparar ao fazer parte do sistema carcerário.

Por um lado os crimes jamais deixarão de existir, seja em Estados ricos ou pobres e por outro lado, podem existir novas formas de punição, as quais o Estado poderia adotar para punir o infrator, corrigindo-o sem que seja humilhado, com a perspectiva de pacificação social, e não criando uma disputa entre o infrator e a sociedade.

A segunda (restaurativa) consiste na reabilitação do indivíduo, que cuida da possibilidade de maior flexibilidade do direito penal, com penas proporcionais e humanizadas, assim como a conciliação como enfoque e a flexibilização de alguns procedimentos, mas sem perder seu caráter punitivo, possibilitando a responsabilidade social sobre o ocorrido, a reparação do dano causado, a prestação de serviços, entre outras.

No cenário atual, o sistema carcerário apresenta inúmeras falhas, o que pode vir a refletir diretamente na recuperação dos detentos.

Os presídios encontram-se, na atualidade, com uma população carcerária muito acima do que é estruturalmente possível. Para corroborar essa afirmação, cabe mencionar o estudo realizado pelo DEPEN (2016), que aponta que o sistema carcerário brasileiro apresentava em 2006 um déficit de 358.663 mil vagas. E é preciso dizer que estes números hoje devem estar significativamente maiores.

Estudos mostram que mais de $40 \%$ dos presos provisórios ainda não foram condenados, e destes, mais da metade são inocentados ${ }^{11}$. Colabora com esse número o fato de que a quatidade de Defensores Públicos no Brasil não consegue atender nem mesmo $1 / 3$ desses encarcerados, fazendo com que as pessoas sem condenação ocupem espaços que, na realidade, não existem.

O cumprimento de pena almejado para o Brasil, de acordo com grande parte dos brasileiros, é um que endureça e dificulte o seu

\footnotetext{
${ }^{10}$ Tem que referenciar.

${ }^{11}$ (INFOPEN, 2016)
} 
cumprimento, acreditando que quanto mais degradantes as condições oferecidas pelos presídios, e quanto mais sofrimento houver lá dentro, menor será o número de pessoas que cometerão crimes, pois, dessa forma temerão a punição, e assim será o fim do cumprimento de pena no Brasil.

A sociedade atualmente não faz ideia da extensão dos direitos e garantias que lhe toca, assim como a forma que podem exercitá-los, passando a exigir dos órgãos policiais o exercício de atribuições que não lhes são próprias e que nada têm a ver com a sua missão institucional, o que parece contribuir de forma sensível para a piora nos índices de prevenção e esclarecimento de crimes.

Esse fenômeno, que se ousa nomear excesso de polícia, conforme se procurará analisar, parece prejudicar não apenas a coletividade como o próprio sistema de justiça criminal ${ }^{12}$.

Ainda existe no nosso Código de Processo Penal, resquícios do sistema da íntima convicção - como acontece, por exemplo, nas decisões proferidas pelos jurados nos casos afetos ao Tribunal do Júri - o que é assustador, uma vez que as decisões podem ser de acordo com o convencimento dos julgadores, o que torna o julgamento, em alguns casos, extremamente subjetivo e desprovido de fundamentação nas provas produzidas sob o crivo do princípio do contraditório.

O fato de o julgador não precisar apresentar a fundamentada motivação às suas decisões, acaba por nos levar a um retrocesso no âmbito do direito processual penal, uma vez que pessoas dotadas de uma posição hierárquica superior podem abusar das pessoas indiciadas, que estão à espera de uma decisão que apure a veracidade do fato, pois o dever de motivação e a apresentação de razões levam ao controle do ato judicial, que é uma garantia do indivíduo, proibindo que se julgue sem fundamentação.

A população carcerária no Brasil hoje são, em sua maioria pessoas marginalizadas e de certa forma não reconhecidas pela sociedade devido à "invisibilidade", que decorre de diversos motivos, como desassistência familiar, desequilíbrios e distúrbios psicológicos que na maioria das vezes não são atendidos, a pratica de bullying e o convívio em ambientes prejudiciais à saúde mental de crianças e adultos, a exclusão devido a condições sócio econômicas, e diversos outros fatores, que teriam como ser evitados, e que o encarceramento sem o respeito à dignidade pode vir a prejudicar.

${ }^{12}$ BARBOSA, André Luis Jardini Barbosa. Tese de Doutorado defendida aos 10 de agosto de 2018 junto à Faculdade Autônoma de Direito/FADISP. 
A população carcerária atual abriga, segundo o CNJ 726.712 mil presos, dentre os quais, $96,3 \%$ são homens.

Do universo total de presos no Brasil, 55\% têm entre 18 e 29 anos. Observando-se o critério por estado, as maiores taxas de presos jovens, com menos de 25 anos, são registradas no Acre (45\%), Amazonas $(40 \%)$ e Tocantins (39\%).

Levando em conta a cor da pele, o levantamento mostra que $64 \%$ da população prisional são compostos por pessoas negras. O maior percentual de negros entre a população presa é verificado no Acre $(95 \%)$, Amapá (91\%) e Bahia (89\%).

Quanto à escolaridade, $75 \%$ da população prisional brasileira não chegaram ao ensino médio. Menos de $1 \%$ dos presos tem graduação.

No total, há 45.989 mulheres presas no Brasil, cerca de 5\%, de acordo com o Infopen. Dessas prisões, 62\% estão relacionadas ao tráfico de drogas. Quando levados em consideração somente os homens presos, o percentual é de $26 \%^{13}$. De acordo com o relatório, $89 \%$ da população prisional estão em unidades superlotadas. São $78 \%$ dos estabelecimentos penais com mais presos que o número de vagas. Comparando-se os dados de dezembro de 2014 com os de junho de 2016, o déficit de vagas passou de 250.318 para 358.663 .

A maior parte das classes hipossuficientes, que embora detenham seus direitos estabelecidos nas leis formalmente reconhecidos assim como todo e qualquer cidadão pertencente à uma sociedade, passam por um processo de marginalização social, e luta por reconhecimento e visibilidade, sendo decorrente de uma liberdade indeterminada, apegada ao aspecto meramente jurídico, pois ao dizer de Carvalho, "em uma ação criminosa os sujeitos fazem um uso destrutivo do fato de, como portadores de direito de liberdade não estarem incluídos no convívio social, senão negativamente" 14 .

Portanto, muitas vezes o motivo interno de um criminoso é constituído pela ideia de que o mesmo não se vê incluído na sociedade que rege as leis de todos, iniciando uma luta por honra e visibilidade.

\footnotetext{
${ }^{13}$ DEPEN. Publicado em 08/12/2017, por Andreia Verdélio, Repórter da Agência Brasil - Brasília.

${ }^{14}$ (CARVALHO, 2013, p. 20)
} 


\section{A PROTEĈ̃̃O QUE SE ALMEJA E A FORMA COMO SÃO TRATADOS OS ENCARCERADOS}

O Código Penal brasileiro estabelece as regras gerais do sistema penal, os elementos do crime, quais as penas cabíveis e seus regimes dentre outras regras - mas, ausente, portanto, de tratativa específica no âmbito do Código Penal, fez-se mister a constituição de uma nova legislação cujo objetivo era tratar da questão do cumprimento efetivo da pena aplicada em sede de sentença penal condenatória, a Lei n. 7.210 de 1985.

A Lei de Execução Penal traz logo em seu primeiro artigo seus objetivos, buscando o legislador efetivar o cumprimento da sentença, de forma a proporcionar condições para a harmônica integração social do condenado, bem como delimitar que os direitos restringidos são apenas aqueles atingidos pela sentença, ou seja, nenhuma norma pode prejudicar os direitos fundamentais, por mais duras que sejam, a não ser que seja o caso de estado de exceção, assegurando ainda que de forma alguma haja distinção de natureza racial, social, religiosa ou política, como dito no Art. $5^{\circ}$ da referida lei.

Art. $1^{\circ} \mathrm{A}$ execução penal tem por objetivo efetivar as disposições de sentença ou decisão criminal e proporcionar condições para a harmônica integração social do condenado e do internado.

Art. $3^{\circ}$ Ao condenado e ao internado serão assegurados todos os direitos não atingidos pela sentença ou pela lei.

Parágrafo único. Não haverá qualquer distinção de natureza racial, social, religiosa ou política.

Como podemos perceber a lei busca além da recuperação do condenado, um tratamento com respeito à sua dignidade humana durante $\mathrm{o}$ tempo de privação de sua liberdade, vez que o processo de mero encarceramento significa apenas a retirada do infrator das ruas, reportando à sociedade a ideia de que essa é a melhor solução, já que depois de encarcerado ele não está mais aos olhos da sociedade.

A legislação brasileira faz menção também, ao caráter recuperador da pena, com o objetivo de reintegrar a pessoa presa na sociedade com novos conceitos, trabalhando com o reeducando de forma a ensina-lo conceitos novos que eles não sabiam antes de ingressarem no sistema carcerário, como é o caso, a título de exemplo, o compromisso do 
trabalho, o estudo - como vimos no índice do capítulo anterior mais de $75 \%$ dos presos não concluíram o ensino médio-, o atendimento psicológico para poder atender à alguma das causas que leva o infrator a cometer o crime, dentre outros.

De acordo com a LEP, O Estado, além de assegurar a assistência ao preso durante o cumprimento da pena, também deverá estender essa assistência ao egresso do regime de cumprimento de pena no sistema fechado, objetivando mais uma vez a necessidade de se prevenir o crime e almejar o retorno pacifico no meio social.

O Art. 11 da LEP nos traz de forma taxativa quais são as assistências que o preso terá enquanto cumprir a sua pena, que compreendem a assistência material, à saúde, jurídica, educacional, social e religiosa.

A assistência material se refere a alimentação, o vestuário e instalações higiênicas, bem como buscar atender os presos em suas necessidades pessoais. Os objetos que não forem fornecidos pela administração poderão ser supridos pela compra em locais destinados à venda de produtos permitidos, como disposto nos Arts. $12^{\circ}$ e $13^{\circ}$ da LEP.

A assistência à saúde tem caráter tanto preventivo quanto curativo, e contará com ajuda médica, farmacêutica e odontológica. Em regra o atendimento deverá ser feito na unidade prisional, mas conforme exceção, se não houver condições no presídio será realizada em outro local, mediante autorização da direção do estabelecimento

Quanto à assistência judiciária, dispõe sobre os presos que não têm recursos financeiros para constituir advogado, (Arts. $15^{\circ}$ e $16^{\circ}$, e parágrafos da LEP) e deverão ter acesso à serviços de assistência gratuita, pela Defensoria Pública.

Devido à privação de liberdade, os presos já enfrentam o cumprimento da pena em uma situação "inferiorizada", e dessa maneira, o Estado deve garantir que este detento receberá de forma efetiva a reeducação, e condições mínimas de amparo para seu retorno ao meio social.

Esta assistência social implica em estar sempre, de certa forma, vigiando o preso, para poder atender às necessidades mais remotas, acompanhando seu comportamento, estendendo ainda este direito à família do internado.

Atualmente, no que diz respeito ao tratamento aplicado, inúmeros se fazem os descumprimentos de princípios constitucionais e internacionais, merecendo destaque as numerosas nações que denunciam o 
tratamento desumano e degradante de dentro dos ambientes prisionais, tendo em vista a constante violação dos direitos fundamentais e o total descaso com o cumprimento da lei que visa a ressocialização e a reintegração social.

Quando os reeducandos estão sob a tutela do Estado lhes são retirados também direitos que não foram atingidos pela sentença penal condenatória $^{15}$ (Art. $38 \mathrm{CP}$ ), portanto, não há o que se falar em pena enquanto medida retributiva, vez que está além do proposto na sentença, mais uma vez, aparecendo somente na teoria.

Nos dizeres de Salo de Carvalho:

[...] é lógico que da perda do direito de ir e vir decorrem inúmeras limitações, daí o escopo normativo em suprir o encarcerado das necessidades materiais através do estatuto social positivo - normas que regulam alimentação, vestuário, e instalações higiênicas (Art. 12 LEP); atendimento médico, farmacêutico e odontológico (Art. 14 LEP); assistência jurídica (Art. 15 LEP); instrução escolar e formação profissional (Art. 17 LEP); recreação, orientação, segurança e previdência (Art. 23 LEP); assistência religiosa (Art. 24 LEP); direitos decorrentes de atividade laboral (Art. 28 e seguintes LEP). Tudo porque reconhece-se que o preso apesar de ter sua liberdade restringida não perde todos os direitos adquiridos enquanto cidadão (SALO, 2008, p. 176).

A ausência de reformas nos ambientes prisionais é silenciada por trás dos muros, onde os encarcerados são submetidos à essas péssimas condições de vida, e onde o desrespeito à sua dignidade humana chega a níveis degradantes de inferiorização, vez que, nos dizeres de Soares ${ }^{16}$ : “o preconceito provoca a invisibilidade à medida que projeta sobre a pessoa um estigma que a anula, a esmaga e a substitui por uma imagem caricata, que nada tem a ver com ela, mas expressa bem as limitações internas de quem a projeta".

Quando ocorrem reações dos presos às péssimas condições de vida oferecidas, os mesmos são punidos com sanções penais e administrativas, porém, o que os administradores dos presídios não conseguem enxergar, é que na maioria das vezes esta e uma maneira particular e única dos encarcerados romperem o buraco que os muros conseguem tampar.

\footnotetext{
${ }^{15}$ Art. 38 do Código Penal.

${ }^{16}$ (SOARES, 2005, apud CARVALHO, 2013, p. 19).
} 


\section{A APAC COMO MODELO DE SISTEMA A SER SEGUIDO}

Não tem como negar que o próprio DEPEN reconhece a fragilidade do sistema carcerário nacional, reconhecendo que é preciso que o sistema estatal e outras entidades, inclusive privadas sem fins lucrativos, estejam em constante busca por modelos de aperfeiçoamento.

Esta necessidade de aperfeiçoamento do sistema tem ligação estrita com o desrespeito à dignidade da pessoa humana que atualmente se tem verificado na sistemática atual de cumprimento das penas.

Nessa perspectiva, passa a ser especificamente analisada a APAC -Frutal,

A APAC é a Associação de Proteção e Assistência aos condenados, e surgiu em 1972, na cidade de São José dos Campos - SP, através de um grupo de voluntários cristãos, sob a liderança do advogado e jornalista Dr. Mário Ottoboni. O seu surgimento se deu, num primeiro instante, no presídio de Humaitá, e o seu objetivo era o de evangelizar e dar apoio moral aos presos ${ }^{17}$.

As APACs não possuem finalidade lucrativa, e tem como objetivo a recuperação dos reeducandos, priorizando a escola, o trabalho e a saúde, porém, com observância da execução da pena privativa de liberdade em seu caráter punitivo ${ }^{18}$..

A metodologia da APAC funciona com a valorização humana, dispondo de trabalho dentro das próprias unidades, deixando de lado o ócio que interfere diretamente nos presídios convencionais, onde as celas superlotadas não dão espaço sequer para os presos dormirem, como já citado em capítulo anterior, sem contar as condições insalubres com as quais os presos se veem obrigados a conviver.

A APAC é composta por 12 princípios fundamentais, sendo esses: a participação da comunidade; a ajuda mútua entre recuperandos; o trabalho; religião; assistência jurídica; assistência à saúde; valorização humana; família; formação de voluntários; implantação de centros de

\footnotetext{
${ }^{17}$ Essa era uma forma de proporcionar a criação de uma experiência revolucionária., e antes de 1974 A sigla significava Amando o Próximo Amarás a Cristo, porém, após grupos de voluntários descobrirem, e se interessarem pelo trabalho, dividiram-se em duas organizações diferentes, coexistindo sem interferirem uma na outra, mas se complementando (FBAC, 2019).

${ }^{18}$ A forma de ingresso nas APACS é por meio de uma carta que demonstre interesse do próprio reeducando na instituição, e serve para as penas privativas de liberdade, tanto no regime semi aberto quanto no regime fechado (APAC- FRUTAL, 2018).
} 
reintegração social; observação minuciosa do comportamento do recuperando, para fins de progressão do regime penal; e a Jornada de Libertação com Cristo (CNJ, 2012).

Tendo como propósito a recuperação dos indivíduos, a APAC conta com um número inferior a $15 \%$ de índice de reincidência, como apurado pelo TJMG pelo CNJ no ano de 2012, enquanto no presídio convencional estes números se elevam drasticamente à índices superiores a 70\%, índice retirado da mesma estatística (CNJ, 2012).

Essa diferença que nos assombra, é, mais do que comprovado, um reflexo da falta de humanização para com os reeducandos do sistema convencional, que se apresenta mais como depósito de indivíduos, principalmente após esta análise sobre as APACs e seu método reintegrativo É importante frisar que o envolvimento com as famílias nas APACs também são intensos, promovendo acima de tudo o contato do preso com a sua família, sem que se rompam os laços e o vazio ocupe o lugar da pessoa ausente, dando também maior assistência jurídica tanto ao recuperando quanto à sua família, no que diz respeito à informação, auxilio, entre outros, que correspondam ao respectivo condenado à pena privativa de liberdade.

Os dados já nos mostram que o sistema humanizado nos presídios trazem resultados satisfatórios e inclusivos, devolvendo à sociedade uma pessoa que aprendeu a se comportar e enfrentar os pequenos desafios da vida buscando sempre a melhor forma de mudar o seu padrão de comportamento, sem mais precisar se apoiar no crime, criando novas responsabilidades, e não afastado os reeducandos de sua família, para que esta acompanhe os passos da recuperação, e para que este tenha um lar para onde possa retornar, sem que haja qualquer tipo de receio por parte da própria família ou sociedade.

A conscientização de que o mero depósito de indivíduos nas celas do sistema convencional é ineficaz está aos poucos tomando seu espaço, pois existe um grande abismo de diferença entre a punição pelo crime, e o desejo de que se pague por ele com sofrimento e descaso, como vemos acontecer atualmente. O retorno dos indivíduos para a sociedade, depois de serem tratados como "nada" faz com que estes queiram se vingar ainda mais do estado que ao invés de cumprir com sua proposta de reeducação se esqueceu até mesmo de cumprir com o respeito à dignidade do cidadão.

Deste modo, tem-se afigurado que o modelo de trabalho das APACs bem poderia ser replicado para todo o sistema de cumprimento das penas privativas de liberdade, uma vez que proporciona um retorno 
pacifico e eficaz do reeducando para a sociedade, tendo a certeza de que ensinar, e entender a realidade do próximo são fatores cruciais para a recuperação do indivíduo, fazendo que ao se encontrar novamente no ambiente social, este não sinta ódio e vontade de se vingar de um sistema opressor, mas sinta gratidão por ter aprendido a viver de forma que jamais aprenderia sozinho.

\section{CONSIDERAÇÕES FINAIS}

A presente pesquisa iniciou-se do interesse de analisar o sistema carcerário quanto à sua efetividade, vez que não são respeitados os direitos da dignidade da pessoa humana. Dentro deste aspecto, adotaram-se diversos tipos de estudos, como analises bibliográficas, análise de caso real com visita institucional à uma APAC, para que fosse observado o que difere um ambiente prisional de outro e, sobretudo, a análise se, de fato, era respeitada a dignidade da pessoa humana.

O sistema humanizado dos presídios nos coloca diante de números jamais estimáveis no quesito à reinserção social do sistema convencional, chegando a $70 \%$.

Os estudos realizados permitiram uma percepção de que é possível tornar o sistema carcerário eficaz, tendo em vista que as APACs realizam um trabalho extremamente humanizado das prisões comuns, inclusive tendo como objetivo a efetiva recuperação do indivíduo, e não a mera vingança social.

Diante deste exposto, conclui-se a total ineficácia e carência do sistema carcerário convencional, que busca tão somente a retaliação para uma causa que jamais terá fim, tendo em vista que se torna um ciclo, pois o reeducando sai da cadeia pronto para cometer novos crimes, e tem sua liberdade cerceada novamente, voltando ao mesmo ambiente, depois retornando mais uma vez para a sociedade, e assim o ciclo se repete, não se findando.

A ideia de humanizar e atender as necessidades das pessoas e de sua dignidade, sabendo respeitar que os direitos restringidos são apenas os da sentença penal condenatória, nos colocaria diante de um novo cenário no que diz respeito à recuperação dos detentos, para que estes possam ter uma possibilidade de recuperação e para que saiam, de fato, recuperados, sabendo enfrentar a realidade de maneira diferente da qual sempre se utilizou. 


\section{REFERÊNCIAS BIBLIOGRÁFICAS}

BARBOSA, A. L. J. O excesso policial e o excesso de polícia- a incompatibilidade entre o sistema atual de atuação policial e o estado democrático de direito. Tese de doutorado defendida perante a Faculdade Autônoma de Direito - FADISP, 2018.

CANOTILHO, J. J. G. Direito Constitucional. 6. ed. Coimbra: Livraria Almedina, 1993.

CARVALHO, S. Pena e garantias, $3^{\circ}$ edição, editora Lumen Juris, 2008, RJ.

CARVALHO, T. F. Criminologia, (in)visibilidade, reconhecimento- o controle penal da subcidadania no Brasil, Revan, 2013, RJ.

CARVALHO, R. C.; COELHO V. M. C. Direitos fundamentais: evolução e colisão, 2016. Disponível em: <https://jus.com.br/artigos/54481/direitos-fundamentais-evolucao-ecolisao?fbclid=IwAR3dX3vHj-pUajlhQ1IO2ppMj6AeQelkftqs1YB3Yvf6mzyurryN4oNINKc >. Acesso em 13/09/2018.

DEPEN. Disponível em: <http://depen.gov.br/DEPEN/depen/sisdepen/infopen/infopen>. Acesso em: 06/09/2018.

DEPEN. Disponível em: <http://depen.gov.br/DEPEN/depen/sisdepen/infopen/infopen>. Acesso em: $10 / 06 / 2018$

DEPEN. RELATÓRIO. Disponível em:

<http://depen.gov.br/DEPEN/depen/sisdepen/infopen/relatorio_2016_22-11.pdf〉. Acesso em: $02 / 06 / 2018$

FALCONI, R. Sistema presidial: reinserção social, editora Ícone, 1998, SP.

HUNGRIA, N. Comentários ao Código Penal. Rio de Janeiro: Forense, 1949.

INFOPEN. Levantamento Nacional de Informações Penitenciárias - Infopen, Junho/2016. Secretaria Nacional de Segurança Pública, Junho/2016; Fórum Brasileiro de Segurança Pública, dezembro/2015; IBGE, 2016.

LEI ${ }^{\circ}$ 7.209, de 11.7.1984. $163^{\circ}$ da Independência e $96^{\circ}$ da República, Brasil.

LEI $n^{\circ} 12.403,4.5 .2011 .190^{\circ}$, da Independência e $123^{\circ}$ da República, Brasil.

LEI n ${ }^{\circ} 13.163,9.7 .2015 .194^{\circ}$ da Independência e $127^{\circ}$ da República, Brasil.

MIR PUIG, S. Estado, pena y delito. montevideo: B de F, 2012 (maestros del derecho penal, n21).

NUCCI, G. S. Manual de Direito Penal - Parte Geral e Especial. São Paulo: Editora Revista dos Tribunais, 2005, p. 335.

NUCCI, G. S. Manual de Direito Penal, 10 edição, ed Forense, RJ, 2014. 
RIVAS, C. Direitos Fundamentais Constitucionais e sua Eficácia Vertical e Horizontal, 2016. Disponível em: <https://caiorivas.jusbrasil.com.br/artigos/387103378/direitos-fundamentaisconstitucionais-e-sua-eficacia-vertical-ehorizontal?fbclid=IwAR0_FoQb45xWGMqGBtWOPM3L_GBGo1YsVhBd1EL0NMYKxI4mbi5Qp 1Tao2o>. Acesso em: 23/05/2018.

SUN, E. Pena, Prisão e Penitência: A arquitetura prisional no brasil. 2015, p. 86

VERDÉLIO, A. Com 726 mil presos, Brasil tem terceira maior população carcerária do mundo. Publicado em 8/12/2017. Disponível em: <http://agenciabrasil.ebc.com.br/geral/noticia/201712/populacao-carceraria-do-brasil-sobe-de-622202-para-726712-pessoas >. Acesso em: 05/04/2018. 